\title{
Incapacity, Handicap, and Oxidative Stress Markers of Male Smokers With and Without COPD
}

\author{
Syrine Ben Moussa, Sonia Rouatbi MD PhD, and Helmi Ben Saad MD PhD
}

\begin{abstract}
BACKGROUND: Mechanisms of incapacity and quality of life (QOL) of smokers with COPD and those free from COPD (non-COPD) are still unclear. The aims of this work were to compare the submaximal exercise, the QOL, and the blood and lung oxidative stress biomarker data of smokers without and with COPD. METHODS: Thirty-two male-smokers 40-60 y old were included (16 with COPD). QOL (Saint George Respiratory Questionnaire) and physical activity (Voorrips questionnaire) scores were determined. Blood sample levels of malondialdehyde, protein sulfhydryl, and glutathione were measured. Fraction of exhaled nitric oxide, plethysmographic data, and 6-min walk distance (6MWD) were collected. All data are presented as mean \pm SD, except oxidative stress biomarkers expressed as mean $\pm \mathrm{SE}$. Correlation coefficient $(r)$ evaluated the association between oxidative stress biomarkers and 6MWD, QOL, and physical activity data. RESULTS: Two age- and amount of tobacco used-matched groups of smokers were included. Compared with the non-COPD group, the COPD group had significantly lower 6MWD (573 \pm 63 vs $476 \pm 53 \mathrm{~m})$ and physical activity score $(7.14 \pm 1.50$ vs $2.86 \pm 1.50)$ and significantly worse QOL $(19.47 \pm 15.33$ vs $47.70 \pm 16.73)$ and lower glutathione level $(39.44 \pm 6.28$ vs $24.67 \pm 5.41 \mu \mathrm{g} / \mathrm{mL})$. The COPD group malondialdehyde level was significantly correlated with $6 \mathrm{MWD}$, symptoms, and QOL scores (good $r$ value between 0.50 and 0.70 ). The non-COPD group fraction of exhaled nitric oxide and glutathione levels were significantly correlated with leisure activity score and $6 \mathrm{MWD}$, respectively (good $\mathbf{r}$ value between 0.50 and 0.70). CONCLUSIONS: Compared with the non-COPD group, the COPD group had a marked decrease in submaximal exercise data and in QOL score. Oxidative stress could be one explanation of incapacity and handicap observed in the COPD group. Key words: smokers; oxidative stress; 6MWT; QOL; physical activity. [Respir Care 2016;61(5):668-679. (C) 2016 Daedalus Enterprises]
\end{abstract}

\section{Introduction}

COPD, the primary cause of which is tobacco smoke, is a preventable and treatable disease. ${ }^{1,2}$ This chronic disease

\footnotetext{
The authors are affiliated with the Service of Physiology and Functional Explorations, Farhat Hached Hospital, Sousse, Tunisia. Mr Ben Moussa is also affiliated with the Sciences Faculty of Bizerte, University of Carthage, Tunis, Tunisia. Drs Rouatbi and Ben Saad are also affiliated with the Laboratory of Physiology, and Dr Ben Saad is also affiliated with Research Laboratory LR14ES05: Interactions of the Cardiopulmonary System, Faculty of Medicine of Sousse, University of Sousse, Sousse, Tunisia.
}

Drs Rouatbi and Ben Saad contributed equally to this work.

The authors have disclosed no conflicts of interest. has gained interest as a major public health concern, and it is now considered as one of the leading causes of disability. ${ }^{2}$

To better investigate this chronic disease, it would be wise to refer to the World Health Organization's most recent categorization of its natural history (http:// www.who.int/classifications/icf/en/, Accessed October 9, 2015), reporting 3 evolutionary phases: deficiency, incapacity, and handicap. Although mechanisms of COPD de-

\footnotetext{
Supplementary material related to this paper is available at http:// www.rcjournal.com.

Correspondence: Syrine Ben Moussa, Laboratory of Physiology, Faculty of Medicine of Sousse, Mohamed Karoui Street, Sousse 4000, Tunisia. E-mail: bm.syrine@gmail.com.
}

DOI: $10.4187 /$ respcare. 04420 
ficiency have already been extensively explored, ${ }^{3-5}$ those of the remaining 2 phases are understudied. ${ }^{6}$ The assessment of incapacity is considered important, because it alone can predict the prospective functioning of the subject.7.8 This is the determination of exercise ease through data from an outside test, such as the 6-min walk test (6MWT). ${ }^{7,8}$ The skill of walking is a reflection of the ability to maintain a number of daily life activities for patients. ${ }^{7,8}$ Therefore, it is an important quality-of-life (QOL) component. ${ }^{7,8}$ The handicap, which is the psychosocial impact of the chronic disease, can be objectively evaluated by the assessment of QOL ${ }^{9}$ and/or physical activity status. ${ }^{10}$ In a previous local study, ${ }^{3}$ aiming to investigate the oxidative stress associated with tobacco smoke, the authors recommended evaluating its effects with submaximal exercise capacity and QOL. Finally, an integrative vision was advanced to evaluate subjects with COPD, through the BODE index, which is a simple multidimensional grading system predicting the risk of death. ${ }^{11}$

Recently, the American Thoracic Society/European Respiratory Society ${ }^{6}$ have recommended studies that contribute to a better understanding of COPD pathogenesis and impact and that elucidate pathways driving the chronic inflammatory response and oxidative stress that lead to the abnormalities characteristic of COPD. The present casecontrol study aimed to add to the current body of literature by evaluating the submaximal exercise, the QOL, and the blood and lung oxidative stress biomarker data of smokers free from COPD (non-COPD) and with COPD. The main null hypothesis is that there will be no difference between submaximal data mean values in both groups.

\section{Populations and Methods}

A part of the present study methodology was previously published in another study ${ }^{3}$ that aimed to investigate oxidative stress in the blood or lungs associated with tobacco smoke and to evaluate its effect with pulmonary function data and its relation to physical activity.

\section{Study Design}

This was a case-control study performed from April to November 2013 in Farhat Hached Hospital (Sousse, Tunisia). More information about the city and the prevalence of smoking and COPD in that region was published previously. ${ }^{3}$ In brief, $7.8 \%$ of the local population $\geq 40 \mathrm{y}$ old had COPD. ${ }^{3}$

The study was conducted in accordance with the Declaration of Helsinki. Participants provided written consent, and the study protocol was approved by the ethics committee of the hospital (approval 2204/2013).

\section{QUICK LOOK}

\section{Current knowledge}

Recently, scholarly societies have recommended studies that contribute to a better understanding of COPD pathogenesis and impact and that elucidate pathways driving the chronic inflammatory response and oxidative stress that lead to the abnormalities characteristic of COPD.

\section{What this paper contributes to our knowledge}

Compared with the non-COPD group, the COPD group had significantly lower 6-min walk distance (6MWD) by $\sim 97 \mathrm{~m}$, lower physical activity scores, and worse quality-of-life scores. Compared with the non-COPD group, the COPD group had significantly lower levels of glutathione. Stress oxidative biomarkers were correlated with 6MWD (malondialdehyde for the COPD group and glutathione for the non-COPD group) and quality-of-life scores (malondialdehyde for the COPD group and $\mathrm{F}_{\mathrm{ENO}}$ for the non-COPD group).

\section{Sample Size}

The null hypothesis ${ }^{12}$ was $\mathrm{H}_{0}: \mathrm{m}_{1}=\mathrm{m}_{2}$, and the alternative hypothesis was $\mathrm{H}_{\mathrm{a}}: \mathrm{m}_{1}=\mathrm{m}_{2}+\mathrm{d}$, where $\mathrm{d}$ is the difference between 2 means, and $n_{1}$ and $n_{2}$ are the sample sizes for the non-COPD and COPD groups of smokers, such that $N=n_{1}+n_{2}$. The required sample size was estimated using a specific formula ${ }^{12}$ (detailed in the supplemental materials at http://www.rcjournal.com) to detect a difference between 2 means with a power of $99 \%$ and an $\alpha$ level of $1 \%$. The total sample size for the study was 32 smokers (16 non-COPD and 16 COPD).

\section{Population}

The population was described previously. ${ }^{3}$ In brief, subjects with COPD were recruited from the local respiratory department. The non-COPD smoker sample was a convenience sample recruited from the staff of the local Faculty of Medicine and/or hospital as well as from acquaintances of people involved in the study.

Only male smokers ( $\geq 5$ pack-years, age $40-60$ y) free from asthma, allergies, pulmonary tuberculosis, or recent respiratory tract infection (within the last $7 \mathrm{~d}$ ) were included. Additional exclusion criteria included narghile smokers ${ }^{13} ; 6 \mathrm{MWT}$ contraindications ${ }^{7,8}$ (detailed in the supplementary data); diabetes lasting for $>5 \mathrm{y}$; and rheumatologic, orthopedic, or surgical diseases interfering with walking. An acute response to inhaled bronchodilator 
$\left(>500 \mathrm{~mL} \text { and } 20 \% \text { of } \mathrm{FEV}_{1} \text { or } \mathrm{FVC}\right)^{14}$ and imperfect performance of the respiratory and 6MWT maneuvers (described in the supplementary data) were applied as exclusion criteria.

Smokers must have stopped smoking for $\geq 6 \mathrm{~h},{ }^{15-18}$ and they were asked to fast (no eating or drinking) for $\geq 10 \mathrm{~h}$ before coming to the hospital. ${ }^{3}$ Smokers were asked not to participate in strenuous activity for $1 \mathrm{~h}$ before the fractional exhaled nitric oxide $\left(\mathrm{F}_{\mathrm{ENO}}\right)$ measurements and 6MWT. ${ }^{17-19}$

Smokers were divided into 2 groups, taking into account the post-bronchodilator $\mathrm{FEV}_{1} / \mathrm{FVC}$ ratio. Smokers with $\mathrm{FEV}_{1} / \mathrm{FVC}>0.70$ were considered as free from COPD and qualified for the non-COPD smoker group. ${ }^{4}$ Those with $\mathrm{FEV}_{1} / \mathrm{FVC} \leq 0.70$ were considered members of the COPD smoker group. ${ }^{4}$ Subjects with COPD were clinically stable, with no worsening of symptoms, need of increase of medication, emergency care, or hospitalization within the previous 4 weeks. Duration of the COPD and medical treatments were recorded.

In order to avoid misinterpretation of plethysmographic data (especially reversibility test data) and/or $\mathrm{F}_{\mathrm{ENO}}$ data (influenced by inhaled glucocorticoids) ${ }^{20}$ and/or stress oxidative data (influenced by vitamin use) ${ }^{21}$ and/or 6-min walk distance (6MWD) (influenced by bronchodilator use), ${ }^{22}$ subjects with COPD were asked to stop, temporarily before measurements, some medicine use (inhaled corticosteroids [for 3 weeks], inhaled $\beta$-adrenergic agonists [for $2 \mathrm{~d}$ ], and oral theophylline or inhaled $N$-acetylcysteine or vitamin $\mathrm{C}$ and/or $\mathrm{E}$ [for 1 week]).

\section{Study Protocol and Collected Data}

Smokers were evaluated only for 1 day. The study protocol was in the following order: (1) fasting blood sample: malondialdehyde, glutathione, and protein sulfhydryl levels; (2) medical questionnaire (clinical data [sputum, cough, dyspnea, chest pain, wheezing, medical and surgical histories, and medication use], schooling and socioeconomic levels, and cigarette consumption), physical activity (household, sporting, and leisure activities),${ }^{10}$ and QOL (symptoms, activity, and impacts) ${ }^{9}$ scores; (3) anthropometric data: age (chronological lung age), weight, height, and body mass index (BMI); (4) $\mathrm{F}_{\mathrm{ENO}}$ data; (5) plethysmographic data before/after bronchodilator: $\mathrm{FVC}, \mathrm{FEV}_{1}$, $\mathrm{FEV}_{1} / \mathrm{FVC}$, mid-maximal expiratory flow, slow vital capacity, thoracic gas volume, residual volume, total lung capacity, and estimated lung age; (6) 6MWT data: 6MWD (primary outcome), heart rate, $\mathrm{S}_{\mathrm{pO}_{2}}$, systolic blood pressure, diastolic blood pressure, dyspnea (visual analog scale), BODE index, ${ }^{11}$ and estimated cardiorespiratory and muscle chain age.

\section{Socioeconomic Data, Tobacco Use, and Physical Activity and QOL Evaluation}

Two schooling levels (low [illiterate or primary education] and high [secondary or university education]) and socioeconomic levels (unfavorable [unskilled worker or jobless] and favorable [skilled worker, farm owner, or manager]) were defined. ${ }^{3}$

Active smoking was assessed by series of questions about past and current activity. ${ }^{3}$ Cigarette smoking and narghile use were evaluated, respectively, in pack-years and in narghile-years. ${ }^{13} \mathrm{~A}$ narghile is a water pipe that is used to smoke a tobacco preparation burned by charcoal embers; the smoke is cooled by passing through water before being inhaled. ${ }^{13}$

QOL was evaluated by the Saint George Respiratory Questionnaire (SGRQ). ${ }^{9}$ An Arabic translation, but not validated, version of this questionnaire was applied. The SGRQ, self-administrated at the laboratory on the day of the 6MWT, is an airway disease-specific questionnaire divided into 3 subscales: symptoms, activity, and impacts ( 8,16 , and 26 items, respectively). Scores were calculated using score calculation algorithms. Smokers were handed the questionnaire by one researcher (SBM) for completion.

A translated version of the Voorrips et al ${ }^{10}$ physical activity questionnaire was filled out by each smoker, and household, sporting, and leisure activities were evaluated to yield a total physical activity score. The questionnaire was described previously. ${ }^{3}$ According to the total physical activity score, 2 groups were defined (non-active [score $<9.4$ ] and active [score $\geq 9.4$ ]).

\section{Physical Examination}

The following anthropometric data were verified, measured, or calculated: age (y), height $(\mathrm{m})$, weight $(\mathrm{kg})$, and BMI $\left(\mathrm{kg} / \mathrm{m}^{2}\right) .{ }^{3}$ Depending on BMI, the smokers were classified as non-obese $(\mathrm{BMI}<30)$ or obese $(\mathrm{BMI} \geq 30){ }^{3}$

\section{Blood Sample}

The blood sample technique was described previously. ${ }^{3}$ Low levels of glutathione and protein sulfhydryl and a high level of malondialdehyde are signs of significant oxidative stress. ${ }^{23}$

\section{$\mathrm{F}_{\text {ENO }}$ and Plethysmographic Measurements}

These 2 measurements were described previously. ${ }^{3} \mathrm{~F}_{\mathrm{ENO}}$ (ppb), recently recommended as an oxidative biomarker that integrates both airway inflammation and lung function changes, ${ }^{24,25}$ was measured using an online method (electrochemical analyzer, Medisoft, Dinant, Belgium). ${ }^{24}$ The mean of 3 reproducible values was retained. ${ }^{24}$ The ple- 
thysmographic measurements were done according to American Thoracic Society/European Respiratory Society guidelines. ${ }^{15,26}$ COPD diagnosis was confirmed when the post-bronchodilator $\mathrm{FEV}_{1} / \mathrm{FVC}$ was $<0.70 .{ }^{4} \mathrm{COPD}$ air flow limitation severity (based on post-bronchodilator $\mathrm{FEV}_{1}[\%]$ ) was classified as follows2: mild, $\mathrm{FEV}_{1} \geq 80 \%$; moderate, $50 \% \leq \mathrm{FEV}_{1}<80 \%$; severe, $30 \% \leq \mathrm{FEV}_{1}<50 \%$; and very severe, $\mathrm{FEV}_{1}<30 \%$. Estimated lung age was calculated. ${ }^{27}$

\section{MWT Measurements}

The 6MWT procedure was described extensively elsewhere. $7,8,17,18,28$ It was conducted along a straight corridor according to American Thoracic Society/European Respiratory Society guidelines. ${ }^{7,8}$

All smokers performed the 6MWT for the first time with standardized encouragement. ${ }^{7,8}$ The following data were collected at rest and at the end of the 6MWT: heart rate (beats/min, \% predicted maximum heart rate), $\mathrm{S}_{\mathrm{pO}_{2}}$ (\%), dyspnea (visual analog scale), and blood pressure $(\mathrm{mm} \mathrm{Hg})$. The $6 \mathrm{MWD}(\mathrm{m}, \% \text { predicted })^{28}$ and the number of stops during the test were noted.

The 6MWD lower limit of normal was calculated by subtracting $89 \mathrm{~m}$ from the predicted 6MWD value. ${ }^{28}$ The estimated cardiorespiratory and muscle chain age (y) was calculated. ${ }^{17,18}$ Dyspnea during the 6MWT was quantified from 0 (no breathlessness) to 10 (maximum breathlessness) using the visual analog scale. ${ }^{29}$

The following definitions, described elsewhere, 7,8,17,18,28 were applied: (1) walk intolerance: abnormal 6MWD (less than the lower limit of normal $)^{28}$ and/or stops during the $6 \mathrm{MWT}^{28}$ and/or abnormal dyspnea end (visual analog scale score $>5 / 10)^{29}$; (2) clinical desaturation: $\Delta \mathrm{S}_{\mathrm{pO}_{2}}$ (equal to $\left.\mathrm{S}_{\mathrm{pO}_{2} \text { end }}-\mathrm{S}_{\mathrm{pO}_{2} \text { rest }}\right)>5$ points ${ }^{28,30}$; (3) chronotropic insufficiency: an ending heart rate of $<60 \%$ predicted. ${ }^{28,31}$

\section{BODE Index}

The BODE index, a multidimensional index ranging from 0 to 10 points, includes 4 items: BMI (B), degree of air flow obstruction $(\mathrm{O})$ evaluated by the post-bronchodilator $\mathrm{FEV}_{1}(\%)$, dyspnea (D) evaluated by the Modified Medical Research Council scale, ${ }^{11}$ and exercise (E) evaluated by the 6MWD $(\mathrm{m})$. Higher scores indicate a greater risk of death. ${ }^{11}$

\section{Statistical Analysis}

The analysis of variable distribution was performed using the Kolmogorov-Smirnov test. Quantitative data distributions were normal and expressed as mean \pm SD. For more precision, the oxidative stress biomarker data were expressed as mean \pm SE. Qualitative data were expressed as $n(\%)$.
The Mann-Whitney U test and chi-square test were used to compare the 2 groups' quantitative and qualitative data, respectively. The Wilcoxon test was used to compare each group's estimated lung age and estimated cardiorespiratory and muscle chain age with the chronological lung age.

Pearson product-moment correlation coefficients (r) evaluated the associations between oxidative stress biomarkers, submaximal exercise, QOL data and BODE index. An $r>0.70$ was considered as high, $r$ between 0.50 and 0.70 was considered good, $r$ between 0.30 and 0.50 was considered fair, and $\mathrm{r}<0.30$ was considered to represent weak or no association. ${ }^{32}$ All mathematical computations and statistical procedures were performed using Statistica (StatSoft, Inc., Tulsa, Oklahoma). Significance was set at .05 .

\section{Results}

\section{Characteristics of the 2 Smoker Groups}

Table 1 presents the characteristics of the 2 groups. They were matched by age and by amounts of tobacco used. There was no significant statistical difference between the 2 groups in schooling or socioeconomic level or in clinical or pathological data. Compared with the nonCOPD group, the COPD group included a lower percentage of obese smokers.

\section{Evaluation of Deficiency}

Table 2 presents the plethysmographic data of the 2 groups. Compared with the non-COPD group, the COPD group had significantly lower $\mathrm{FEV}_{1}, \mathrm{FEV}_{1} / \mathrm{FVC}$, and midmaximal expiratory flow. The estimated lung ages of the COPD and the non-COPD groups were significantly higher than their chronological lung ages: $85 \pm 18$ y versus $49 \pm 5 \mathrm{y}$, respectively $(P<.001)$ and $57 \pm 11$ y versus $47 \pm 4$ y $(P=.004)$. Four, 9,2 , and one subject of the COPD group had mild, moderate, severe, and very severe air flow limitation, respectively.

\section{Evaluation of Incapacity}

Table 3 presents the 6MWT data of the 2 groups. Compared with the non-COPD group, the COPD group had a significantly lower 6 MWD by $\sim 97 \mathrm{~m}(\sim 14 \%)$. The 2 groups had similar 6MWT profiles.

The estimated cardiorespiratory and muscle chain ages of the COPD and non-COPD groups were significantly higher than their chronological lung ages: $109 \pm 9$ y versus $49 \pm 5 \mathrm{y}$, respectively $(P<.001)$ and $86 \pm 16 \mathrm{y}$ versus $47 \pm 4 \mathrm{y}(P<.001)$. 
InCAPacity, Handicap, and Oxidative Stress Markers in Male Smokers

Table 1. Characteristics of the 2 Smoker Groups

\begin{tabular}{|c|c|c|c|}
\hline Characteristic & Non-COPD $(n=16)$ & $\operatorname{COPD}(n=16)$ & $P$ \\
\hline \multicolumn{4}{|l|}{$\begin{array}{l}\text { Anthropometric, tobacco use, physical activity, and } \\
\text { quality-of-life data, mean } \pm \mathrm{SD}\end{array}$} \\
\hline Age, y & $46.54 \pm 4.14$ & $48.99 \pm 5.33$ & .18 \\
\hline Height, m & $1.72 \pm 0.07$ & $1.67 \pm 0.06$ & .02 \\
\hline Weight, kg & $85 \pm 18$ & $68 \pm 14$ & .009 \\
\hline Body mass index, $\mathrm{kg} / \mathrm{m}^{2}$ & $28.7 \pm 5.3$ & $24.6 \pm 5.2$ & .02 \\
\hline Cigarette use, pack-years & $26 \pm 12$ & $30 \pm 19$ & .64 \\
\hline Household activity score & $1.37 \pm 0.52$ & $0.88 \pm 0.31$ & .003 \\
\hline Sporting activity score & $3.30 \pm 1.90$ & $0.33 \pm 0.54$ & $<.001$ \\
\hline Leisure activity score & $2.48 \pm 1.41$ & $1.64 \pm 0.58$ & .15 \\
\hline Physical activity score & $7.14 \pm 1.50$ & $2.86 \pm 0.78$ & $<.001$ \\
\hline Symptom score & $26.38 \pm 18.72$ & $46.38 \pm 22.82$ & .008 \\
\hline Activity score & $27.00 \pm 20.23$ & $63.44 \pm 29.21$ & $<.001$ \\
\hline Impact score & $13.06 \pm 13.57$ & $39.25 \pm 21.58$ & $<.001$ \\
\hline Quality-of-life score & $19.47 \pm 15.33$ & $47.70 \pm 16.73$ & $<.001$ \\
\hline \multicolumn{4}{|l|}{$\begin{array}{l}\text { Obesity, physical activity status, schooling and socioeconomic } \\
\text { levels, clinical, and pathological data, } n(\%)\end{array}$} \\
\hline Obesity status: obese & $7(43.7)$ & $2(12.5)$ & .02 \\
\hline Physical activity status: active & $1(6.2)$ & $0(0.0)$ & .16 \\
\hline Schooling level: high & $10(62.5)$ & $6(37.5)$ & .08 \\
\hline Socioeconomic level: favorable & $5(31.2)$ & $5(31.2)$ & $>.99$ \\
\hline Cough: yes & $5(31.2)$ & $3(18.7)$ & .20 \\
\hline Sputum: yes & $6(37.5)$ & $5(31.2)$ & .36 \\
\hline Dyspnea: yes & $6(37.5)$ & $8(50.0)$ & .23 \\
\hline Chest pain: yes & $3(18.7)$ & $2(12.5)$ & .32 \\
\hline Recent respiratory infection: yes & $0(0.0)$ & $2(12.5)$ & .08 \\
\hline Emphysema: yes & $0(0.0)$ & $0(0.0)$ & $>.99$ \\
\hline High blood pressure: yes & $2(12.5)$ & $3(18.7)$ & .31 \\
\hline Cardiovascular diseases: yes & $0(0.0)$ & $0(0.0)$ & $>.99$ \\
\hline $\begin{array}{l}\text { Surgical history (abdominal, thoracic, orthopedic, or } \\
\text { neurologic): yes }\end{array}$ & $4(25.0)$ & $1(6.2)$ & .07 \\
\hline
\end{tabular}

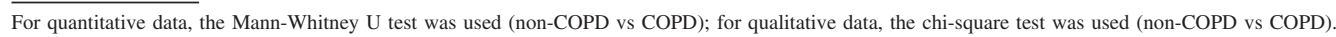

Table 2. Plethysmographic Data of the 2 Smoker Groups

\begin{tabular}{|c|c|c|c|}
\hline & Non-COPD $(n=16)$ & $\operatorname{COPD}(n=16)$ & $P$ \\
\hline$\%$ predicted $\mathrm{FEV}_{1}$ & $88 \pm 10$ & $62 \pm 18$ & $<.001$ \\
\hline$\%$ predicted FVC & $95 \pm 11$ & $87 \pm 18$ & .14 \\
\hline $\mathrm{FEV}_{1} / \mathrm{FVC}$ (absolute value) & $0.76 \pm 0.03$ & $0.58 \pm 0.08$ & $<.001$ \\
\hline$\%$ predicted mid-maximal expiratory flow & $63 \pm 14$ & $26 \pm 11$ & $<.001$ \\
\hline$\%$ predicted slow vital capacity & $91 \pm 12$ & $83 \pm 16$ & .13 \\
\hline$\%$ predicted total lung capacity & $87 \pm 16$ & $92 \pm 14$ & .40 \\
\hline$\%$ predicted residual volume & $86 \pm 41$ & $106 \pm 38$ & .16 \\
\hline$\%$ predicted thoracic gas volume & $105 \pm 37$ & $117 \pm 29$ & .13 \\
\hline
\end{tabular}

Data are mean $\pm \mathrm{SD}$. Plethysmographic data are measured before bronchodilator use and expressed as percentages of predicted values, except for $\mathrm{FEV}_{1} / \mathrm{FVC}$, expressed as an absolute value. The Mann-Whitney U test was used (non-COPD vs COPD).

\section{Evaluation of the Social Disadvantage}

There was no statistical significant difference between the 2 groups' physical activity status (see Table 1). Com- pared with the non-COPD group, the COPD group had significantly lower household, sporting, leisure, and physical activity scores and had significantly higher symptom, activity, impact, and QOL scores (see Table 1). 
Table 3. 6-Min Walk Test Data of the 2 Smoker Groups

\begin{tabular}{|c|c|c|c|}
\hline & Non-COPD $(n=16)$ & $\operatorname{COPD}(n=16)$ & $P$ \\
\hline \multicolumn{4}{|c|}{ Resting (rest) and ending (end) 6MWT data, mean \pm SD } \\
\hline Heart rate ${ }_{\text {rest }}$, bpm & $70 \pm 11$ & $68 \pm 5$ & .84 \\
\hline Heart rate $_{\text {rest }}, \%$ & $40 \pm 6$ & $39 \pm 3$ & .92 \\
\hline Heart rate $_{\text {end }}$, bpm & $95 \pm 16$ & $99 \pm 13$ & .44 \\
\hline Heart rate $e_{\text {end }}, \%$ & $54 \pm 10$ & $57 \pm 8$ & .34 \\
\hline Systolic blood pressure $_{\text {rest }}, \mathrm{mm} \mathrm{Hg}$ & $117 \pm 9$ & $119 \pm 8$ & .40 \\
\hline Systolic blood pressure $_{\text {end }}, \mathrm{mm} \mathrm{Hg}$ & $120 \pm 10$ & $116 \pm 7$ & .44 \\
\hline Diastolic blood pressure $_{\text {rest }}, \mathrm{mm} \mathrm{Hg}$ & $81 \pm 4$ & $83 \pm 6$ & .40 \\
\hline Diastolic blood pressure $_{\text {end }}, \mathrm{mm} \mathrm{Hg}$ & $80 \pm 5$ & $81 \pm 6$ & .95 \\
\hline $\mathrm{S}_{\mathrm{pO}_{2} \text { rest }}, \%$ & $97 \pm 1$ & $98 \pm 3$ & $>.99$ \\
\hline $\mathrm{S}_{\mathrm{pO}_{2} \text { end }}, \%$ & $96 \pm 2$ & $96 \pm 4$ & .59 \\
\hline Dyspnea $_{\text {rest }}$, VAS & $0.31 \pm 1.25$ & $0.56 \pm 1.55$ & .78 \\
\hline Dyspnea $_{\text {end }}$, VAS & $1.38 \pm 2.53$ & $2.81 \pm 3.37$ & .29 \\
\hline $6 \mathrm{MWD}, \mathrm{m}$ & $573 \pm 63$ & $476 \pm 53$ & $<.001$ \\
\hline$\%$ predicted $6 \mathrm{MWD}$ & $76 \pm 9$ & $62 \pm 5$ & $<.001$ \\
\hline No. of stops & $0 \pm 0$ & $0 \pm 1$ & .78 \\
\hline BODE index & $1 \pm 1$ & $2 \pm 2$ & $>.99$ \\
\hline \multicolumn{4}{|l|}{ 6MWT profile, $n(\%)$} \\
\hline Abnormal 6MWD & $15(93.7)$ & $16(100)$ & .14 \\
\hline Chronotropic insufficiency & $11(68.7)$ & $9(56.2)$ & .24 \\
\hline Abnormal dypnea $\mathrm{end}_{\mathrm{e}}$ & $3(18.7)$ & $4(25.0)$ & .31 \\
\hline Stop during the walk & $0(0.0)$ & $1(6.2)$ & .16 \\
\hline Desaturation during walk & $1(6.2)$ & $3(18.7)$ & .15 \\
\hline \multicolumn{4}{|c|}{$\begin{array}{l}\text { For quantitative data, the Mann-Whitney U test was used (non-COPD vs COPD); for qualitative data, the chi-square test was used (non-COPD vs COPD). } \\
6 \mathrm{MWT}=6 \text {-min walk test }\end{array}$} \\
\hline
\end{tabular}

\section{Oxidative Stress Biomarker Levels of the 2 Smoker Groups}

No significant difference was found between the $\mathrm{F}_{\mathrm{ENO}}$ means \pm SE of the non-COPD and COPD groups $(14 \pm 2$ ppb vs $15 \pm 2 \mathrm{ppb}$, respectively, $P=.25$ ).

Figure 1 presents the oxidative stress biomarkers levels of the 2 groups. Compared with the non-COPD group, the COPD group had significantly lower levels of glutathione. However, malondialdehyde and protein sulfhydryl levels were similar for the 2 groups.

\section{Relationship Between Stress Oxidative Biomarkers Levels, Submaximal Exercise, and QOL Data}

Table 4 presents the $r$ value between oxidative stress biomarkers levels and 6MWT and physical activities and QOL data of the 2 groups. In the COPD group, only malondialdehyde was found to be significantly correlated with 6MWD, $\Delta \mathrm{S}_{\mathrm{pO}_{2}}$, symptom score, and QOL score. In the non-COPD group, $\mathrm{F}_{\mathrm{ENO}}$ was significantly correlated with leisure activity score, and glutathione was significantly correlated with 6MWD.

\section{Discussion}

In the present study, 2 age- and amount of tobacco used-matched groups of smokers of $>5$ pack-years $(16$ non-COPD and 16 COPD) were compared. Compared with the non-COPD group, the COPD group had significantly lower 6MWD (by 14\%) and physical activity score, significantly worse QOL, and lower glutathione level. The COPD group malondialdehyde level was significantly correlated with 6MWD, symptom score, and QOL score. The non-COPD group $\mathrm{F}_{\mathrm{ENO}}$ and glutathione levels were significantly correlated with leisure activity score and 6MWD, respectively.

\section{Methodology}

To the best of our knowledge, the present study is the first case-control study having as its main aim a comparison of incapacity and handicap data of 2 age- and amount of tobacco used-matched groups of smokers (COPD vs non-COPD) and an evaluation of the correlation between oxidative stress biomarker levels and their submaximal exercise and QOL data. 

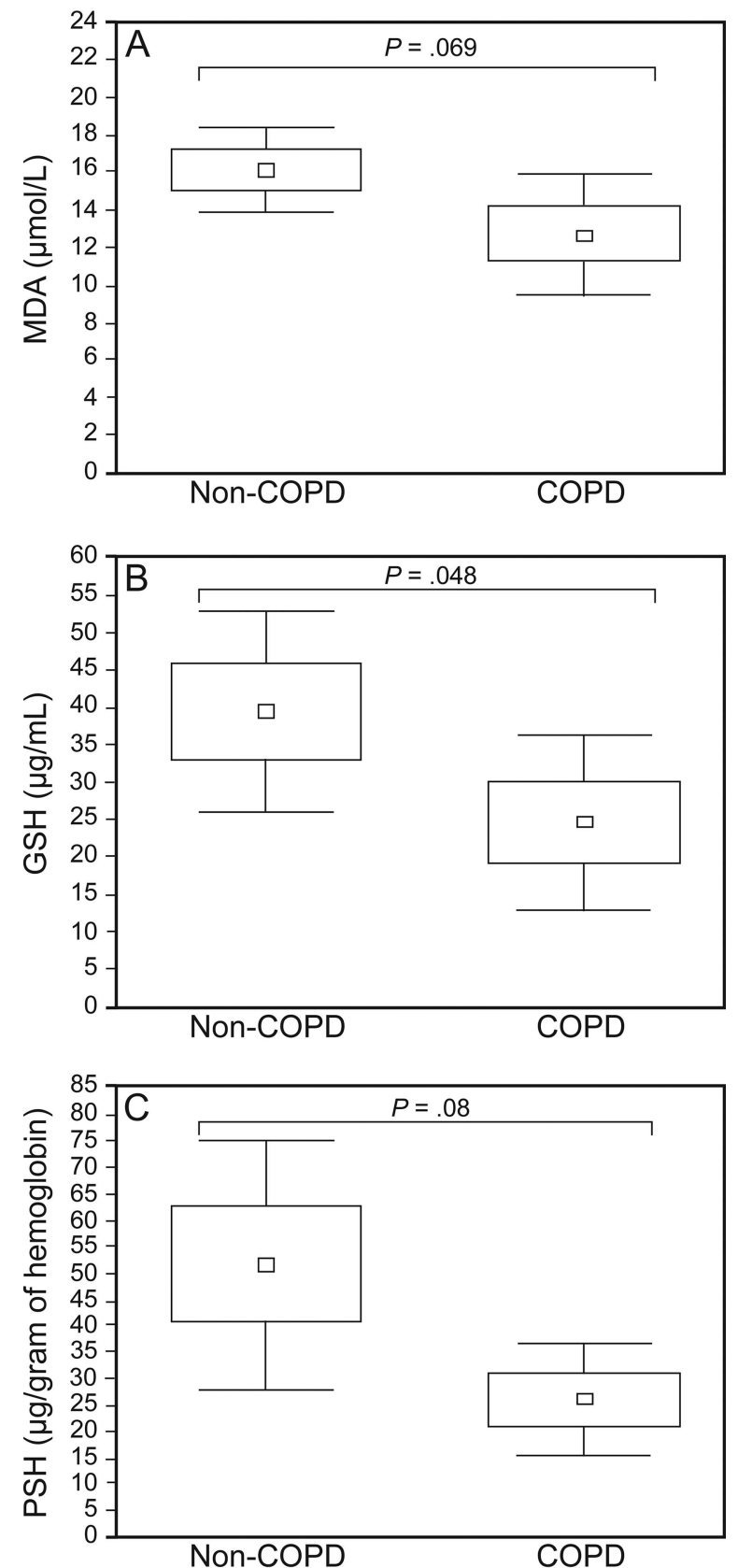

Fig. 1. Oxidative stress levels of 2 groups of smokers. A: Malondialdehyde (MDA) level; B: Glutathione (GSH) level; C: Protein sulfhydryl (PSH) level. Compared with the group without COPD, subjects with COPD had significantly lower levels of GSH (means $\pm \mathrm{SE}$ of $39.44 \pm 6.28 \mu \mathrm{g} / \mathrm{mL}$ vs $24.67 \pm 5.41 \mu \mathrm{g} / \mathrm{mL}$, respectively, $P=.048$ ). However, malondialdehyde and protein sulfhydryl levels were similar for the 2 groups (means \pm SE of $16.18 \pm 1.06$ $\mu \mathrm{mol} / \mathrm{L}$ vs $12.73 \pm 1.49 \mu \mathrm{mol} / \mathrm{L}$, respectively $[P=.069]$ and $51.37 \pm 11.08 \mu \mathrm{g} / \mathrm{g}$ vs $25.72 \pm 5.03 \mu \mathrm{g} / \mathrm{g}$ of hemoglobin $[P=.08])$. Center points denote the mean, boxes show SE, and whiskers represent $95 \% \mathrm{Cl}$.

Discussion about the study design, inclusion and noninclusion criteria, choice of stress oxidant biomarkers, and plethysmographic measurements was published else- where. ${ }^{3}$ Below, we discuss the 2 between-groups control factors (age and amount of tobacco used), the sample size calculation, and the choice of the SGRQ and the physical activity questionnaires.

Age and amount of tobacco used were applied as control factors to avoid misinterpretation of incapacity and handicap data. On the one hand, spirometric data and 6MWD are age-dependent. ${ }^{28,33}$ On the other hand, there were clear positive dose-effect relationships between smoking cumulative doses and, for example, QOL score (the higher the cumulative dose of smoking, the lower the QOL). ${ }^{34}$

The present study calculated sample size $(n=32 ; 16$ COPD) is deemed to be satisfactory. However, it was smaller than those of Folchini et al ${ }^{35}$ (cross-sectional study, $n=45$ COPD) and Lui et al ${ }^{36}$ (case-control study, $n=150$; 100 COPD, 50 healthy smokers). The above studies aimed to evaluate the oxidative stress and the $\mathrm{C}$-reactive protein in subjects with COPD and their correlation with COPD severity and BODE index ${ }^{35}$ or the correlation between some serum inflammatory biomarkers and BODE index. ${ }^{36}$

The SGRQ was applied because it is the only questionnaire that has a validated French version ${ }^{37}$ and is the most widely used instrument for assessing health-related QOL (HRQOL). ${ }^{9}$ The Voorrips physical activity questionnaire ${ }^{10}$ was applied because it is frequently used to measure habitual physical activity, and it is a validated questionnaire for young as well as elderly people in apparently good health. ${ }^{17,28}$ It is important to highlight that the studies of Liu et $\mathrm{al}^{36}$ and Folchini et $\mathrm{a}^{35}$ have not evaluated their subjects' QOL and physical activity status. The choice of the 6MWT to evaluate submaximal exercise capacity and precautions taken during the walk are discussed in the supplementary data.

\section{Study Limitations}

The present study presented 3 limitations. The first concerned the control groups. In the present study, incapacity, handicap, and oxidative data of 2 groups (non-COPD and COPD smokers) were compared. Other studies have included 3 groups (COPD smokers, healthy smokers, and healthy non-smokers ${ }^{16}$ or active and passive smokers and non-smokers ${ }^{38}$ ). However, taking 3 groups into a single study seems to have little precedent in the literature and raises some questions, such as whether the prevalence of some clinical data (obesity, physical activity status, schooling level, socioeconomic level, clinical and pathological data) in the 3 groups is comparable. ${ }^{3}$ The second limitation concerned the inclusion of obese smokers (see Table 1). Obesity induces systemic oxidative stress ${ }^{39}$ and alters the $6 \mathrm{MWD}^{40}$ and/or QOL. ${ }^{41}$ As in the present study, the nonCOPD group, compared with the COPD group, includes a significantly higher percentage of obese smokers; this could 
Incapacity, Handicap, and Oxidative Stress Markers in Male Smokers

Table 4. Correlation Coefficient (r) Between Stress Oxidative Biomarker Levels and Submaximal Exercise and Quality-of-Life Data in the 2 Smoker Groups

\begin{tabular}{|c|c|c|c|c|c|c|c|c|}
\hline \multirow{2}{*}{ Parameters } & \multicolumn{2}{|c|}{$\mathrm{F}_{\mathrm{ENO}}(\mathrm{ppb})$} & \multicolumn{2}{|c|}{$\mathrm{MDA}(\mu \mathrm{mol} / \mathrm{L})$} & \multicolumn{2}{|c|}{$\begin{array}{c}\mathrm{PSH}(\mu \mathrm{g} / \mathrm{g} \\
\text { hemoglobin) }\end{array}$} & \multicolumn{2}{|c|}{$\mathrm{GSH}(\mu \mathrm{g} / \mathrm{mL})$} \\
\hline & $\mathrm{r}$ & $P$ & $\mathrm{r}$ & $P$ & $\mathrm{r}$ & $P$ & $\mathrm{r}$ & $P$ \\
\hline \multicolumn{9}{|l|}{ 6-min walk distance (m) } \\
\hline Non-COPD & 0.18 & .50 & 0.03 & .92 & 0.32 & .22 & 0.50 & .049 \\
\hline COPD & -0.25 & .36 & -0.63 & .01 & -0.08 & .76 & -0.45 & .08 \\
\hline \multicolumn{9}{|l|}{$\Delta$ heart rate (beats $/ \mathrm{min}$ ) } \\
\hline Non-COPD & -0.20 & .45 & -0.15 & .56 & -0.42 & .10 & -0.47 & .065 \\
\hline COPD & -0.03 & .91 & -0.08 & .76 & 0.40 & .11 & 0.07 & .79 \\
\hline \multicolumn{9}{|l|}{$\Delta \mathrm{S}_{\mathrm{pO}_{2}}(\%)$} \\
\hline Non-COPD & -0.37 & .15 & -0.09 & .74 & -0.05 & .84 & -0.38 & .13 \\
\hline COPD & 0.37 & .15 & -0.52 & .047 & 0.22 & .41 & 0.38 & .15 \\
\hline \multicolumn{9}{|c|}{$\Delta$ systolic blood pressure $(\mathrm{mm} \mathrm{Hg})$} \\
\hline Non-COPD & -0.22 & .40 & 0.23 & .37 & -0.15 & .56 & 0.14 & .58 \\
\hline COPD & 0.12 & .66 & 0.12 & .65 & 0.05 & .84 & 0.00 & .98 \\
\hline \multicolumn{9}{|c|}{$\Delta$ diastolic blood pressure $(\mathrm{mm} \mathrm{Hg})$} \\
\hline Non-COPD & -0.02 & .94 & 0.20 & .44 & -0.03 & .90 & 0.11 & .67 \\
\hline COPD & 0.25 & .35 & 0.28 & .30 & -0.27 & .29 & -0.03 & .90 \\
\hline \multicolumn{9}{|l|}{$\Delta$ dyspnea } \\
\hline Non-COPD & 0.02 & .92 & -0.37 & .15 & 0.21 & .43 & 0.02 & .93 \\
\hline COPD & -0.11 & .67 & 0.27 & .31 & 0.06 & .81 & -0.27 & .31 \\
\hline \multicolumn{9}{|l|}{ BODE index } \\
\hline Non-COPD & 0.18 & .50 & -0.30 & .25 & 0.22 & .39 & 0.08 & .74 \\
\hline COPD & -0.17 & .52 & 0.09 & .11 & 0.21 & .42 & -0.14 & .59 \\
\hline \multicolumn{9}{|l|}{ Leisure score } \\
\hline Non-COPD & 0.52 & .036 & -0.46 & .07 & -0.02 & .91 & -0.08 & .75 \\
\hline COPD & 0.07 & .78 & -0.19 & .48 & -0.11 & .66 & -0.03 & .89 \\
\hline \multicolumn{9}{|l|}{ Sports score } \\
\hline Non-COPD & -0.41 & .10 & 0.22 & .40 & -0.10 & .70 & -0.05 & .83 \\
\hline COPD & -0.18 & .49 & 0.15 & .58 & -0.04 & .88 & -0.01 & .94 \\
\hline \multicolumn{9}{|l|}{ Daily score } \\
\hline Non-COPD & -0.00 & .98 & 0.17 & .50 & 0.06 & .79 & 0.19 & .46 \\
\hline COPD & -0.12 & .64 & 0.36 & .17 & -0.05 & .84 & 0.35 & .18 \\
\hline \multicolumn{9}{|l|}{ Physical activity score } \\
\hline Non-COPD & -0.03 & .88 & -0.09 & .72 & -0.13 & .62 & -0.08 & .76 \\
\hline COPD & -0.12 & .65 & 0.09 & .72 & -0.13 & .61 & 0.10 & .70 \\
\hline \multicolumn{9}{|l|}{ Symptom score } \\
\hline Non-COPD & -0.27 & .30 & 0.08 & .76 & -0.13 & .62 & -0.15 & .56 \\
\hline COPD & -0.32 & .21 & 0.57 & .02 & 0.04 & .88 & -0.00 & .98 \\
\hline \multicolumn{9}{|l|}{ Activity score } \\
\hline Non-COPD & -0.23 & .37 & 0.32 & .22 & -0.15 & .56 & -0.13 & .61 \\
\hline COPD & 0.23 & .37 & 0.33 & .22 & 0.35 & .17 & 0.26 & .33 \\
\hline \multicolumn{9}{|l|}{ Impact score } \\
\hline Non-COPD & -0.06 & .81 & 0.02 & .91 & -0.14 & .59 & -0.22 & .40 \\
\hline COPD & 0.07 & .78 & 0.43 & .10 & 0.09 & .71 & -0.12 & .66 \\
\hline \multicolumn{9}{|l|}{ QOL score } \\
\hline Non-COPD & -0.18 & .50 & 0.16 & .55 & -0.16 & .56 & -0.19 & .45 \\
\hline COPD & 0.10 & .70 & 0.69 & .004 & 0.26 & .31 & 0.06 & .82 \\
\hline $\begin{array}{l}\text { For the non-COPD group, } n=1 \\
\text { FENO }_{\text {ENo fractional exhaled nitric }} \\
\text { MDA = malondialdehyde } \\
\text { PSH = protein sulfhydryl } \\
\text { GSH = glutathione } \\
\Delta=6 \text {-min walk test (end }- \text { res } \\
\text { QOL = quality of life }\end{array}$ & $t=16$. & & & & & & & \\
\hline
\end{tabular}


be a serious limitation (see Table 1). However, the percentage of included obese smokers $(30 \%, 7$ non-COPD and 2 COPD) (see Table 1) was similar to that described in the Tunisian general population ${ }^{42}$ (obesity prevalence was $28 \%$ ), and the present study sample could be a representative sample of the Tunisian population. In addition, the COPD sample of the present study was representative of the COPD population, where obesity prevalence is around $12.5 \% .43$ The last limitation concerns the use of a non-validated version of the SGRQ and the Voorrips questionnaire. In cases where questionnaires unadapted to the local culture are used, the psychometric characteristics in terms of validity, reliability, and sensibility could be a subject of caution.

\section{Results}

The World Health Organization classification of the natural history of chronic diseases (http://www.who.int/ classifications/icf/en/, Accessed October 9, 2015), such as COPD, reports 3 evolutionary phases: deficiency, incapacity, and handicap or social disadvantage. Below, we will discuss the 3 phases in addition to the integrative vision, including the BODE index.

Evaluation of Deficiency. In the present study, compared with the non-COPD group, the COPD group had significantly lower flows and $\mathrm{FEV}_{1} / \mathrm{FVC}$ (see Table 2). The present result was similar to what has been previously published and discussed. ${ }^{3,44,45}$ However, one interesting result of the present study was that smoking significantly accelerated lung aging of the 2 smoker groups, with a marked acceleration in the COPD group versus the nonCOPD group. These results can be used to encourage smoking cessation. ${ }^{27}$

Evaluation of Incapacity. Similar to other studies, ${ }^{46-48}$ the present work reports a statistically significant decrease in submaximal exercise capacity in the COPD group compared with the non-COPD group. The 6MWD decrease of $\sim 97 \mathrm{~m}$ is considered clinically important, since it was higher than the 6MWD 30-m minimal important difference in adults with chronic respiratory disease. ${ }^{7,8}$ For subjects with COPD, there is a strong association between shorter 6MWD and an increased risk of mortality 7,8 and hospitalization and decreased HRQOL. 49

The non-COPD and COPD groups have similar heart rate data. However, they both included higher percentages of subjects with chronotropic insufficiency (see Table 3). It is established that heart rate responses may contribute to performance in the 6MWT in subjects with chronic respiratory disease. ${ }^{7}$

The non-COPD and COPD groups have similar $\mathrm{S}_{\mathrm{pO}_{2}}$ data and included a similar number of subjects with clin- ical desaturation (see Table 3). Oxygen desaturation during a 6MWT provides information regarding exercise-induced desaturation, disease severity, and disease progress. ${ }^{8}$ Exercise-induced desaturation is associated with impaired daily physical activity, faster $\mathrm{FEV}_{1}$ decline, and worse prognosis, ${ }^{50}$ which supports its clinical importance.

The non-COPD and COPD groups have similar dyspnea data. However, they both included higher percentages of subjects with an abnormal dyspnea $a_{\text {end }}$ (see Table 3). Dyspnea, an important determinant of the 6MWD in subjects with COPD, ${ }^{51}$ reflects both the physiology of exercise limitation $^{52}$ and the impact of exercise limitation on daily life. ${ }^{53}$

Another key outcome of the present study was that smoking significantly accelerated the 2 groups' cardiorespiratory muscle chain aging with a marked hastening in the COPD group versus the non-COPD group. It is an unwavering argument suggesting that a program of pulmonary rehabilitation is an excellent axis to follow not only for smokers with COPD but also in smokers free from COPD.

Evaluation of Handicap. In the present study, as in others, ${ }^{54-56}$ compared with the non-COPD group, the COPD group had a significantly worse QOL (see Table 1). For example, Agusti et al ${ }^{56}$ found subjects with COPD to have a significantly lower QOL score when compared with control smokers (SGRQ mean $\pm \mathrm{SD}, 50 \pm 20$ vs $21 \pm 12$, respectively). Whereas almost all included smokers $(n=31)$ had a sedentary life style, compared with the non-COPD group, the COPD group had statistically significantly lower physical activity scores (see Table 1). The above result was similar to that reported by Amorim et al,57 where the COPD group $(n=40)$, when compared with the non-COPD group $(n=40)$, had a significantly greater limitation in activities of daily living $58(33 \pm 11$ vs $21 \pm 2$, respectively).

Many studies have highlighted the importance of HRQOL in the evaluation of COPD severity and support the view that it should be considered, in addition to lung function, to better assess subjects with COPD. ${ }^{59,60}$ According to some guidelines, ${ }^{2,6}$ the aim of clinical control in subjects with COPD includes HRQOL goals (improve QOL and increase physical and emotional participation in everyday activities) in addition to clinical goals. The usefulness of QOL measures is indisputable in the field of descriptive epidemiology. ${ }^{2}$ In clinical practice, it can strengthen the doctor-patient relationship by emphasizing the interest that one carries to the consequences of the disease/symptoms in the patient's daily life. From a public health perspective, it is important to determine the level of physical activity to provide a theoretical basis for the development of appropriate policies and programs to enhance health and prevent the many complications attending physical inactivity. ${ }^{61}$ Physical activity remains the best 
way to maintain body wellness, to ensure daily activities, and to keep good cardiopulmonary function and thus daily physical activity. Physical activity and exercise have been demonstrated to promote health and to avoid and reduce health problems, such as vascular and inflammatory diseases, and to assist with weight management. ${ }^{62}$

Integrative Vision: BODE Index. No significant difference was found between the 2 groups' BODE indexes (see Table 3). The BODE index captures the multidimensional manifestations of COPD. ${ }^{11}$ It is a valuable tool not only in the assessment of severity and progression of COPD, but also in evaluating the response to medical interventions. ${ }^{63}$

How Can the Impairment of the COPD Smokers' 6MWD Be Explained? Several hypotheses can be advanced: alteration of the cardiorespiratory and vascular systems and myopathy. Below is a brief discussion of these hypotheses.

Spirometric data are predictors of 6MWD. ${ }^{28}$ The present study suggests that the alteration of the resting FEV $_{1}$ and mid-maximal expiratory flow data observed in the COPD group when compared with the non-COPD group (see Table 2) could explain the marked difference between their 6MWDs. The alteration of the initial spirometric function limits breathing reserve ${ }^{30}$; thus, the lungs may be a factor limiting the 6MWD. ${ }^{30}$

Hypoxemia, known as a classic muscle deterioration factor, ${ }^{64}$ cannot be retained as a hypothesis, since the 2 groups have similar $\mathrm{S}_{\mathrm{pO}_{2}}$ data and include similar percentages of smokers with a clinical desaturation (see Table 3). Cardiovascular data (such as heart rate and blood pressures) are predictors of 6MWD. ${ }^{65,66}$ However, they cannot be advanced as an explanation, since the 2 groups have similar heart rate and blood pressure data and include similar percentages of smokers with chronotropic insufficiency.

Myopathy is an alteration of the functional, morphological, and metabolic qualities of muscle tissue. ${ }^{67}$ It could be the result of numerous alterations, with the main ones being corticosteroid use, sedentary lifestyle, oxidative stress, inflammation, and apoptosis. ${ }^{68}$ The corticosteroidinduced myopathy ${ }^{69}$ hypothesis is not retained, since corticosteroid use was a non-inclusion criterion. Sedentary lifestyle is known as a predictor of 6MWD decline in healthy subjects ${ }^{39}$ and in subjects with $\mathrm{COPD}^{70}$. Indeed, it has been shown that physical inactivity leads to a change in the typology with increased muscle fiber type II depending on the type I fibers. ${ }^{71}$ Since the physical activity scores of COPD group were significantly lower than these of the non-COPD group (see Table 1), the authors can speculate that sedentary life style is a cause of structural changes and muscle metabolism. ${ }^{72}$ Oxidative stress is known as a major cause of myopathy in subjects with COPD. ${ }^{67,73}$ The present paper supports this hypothesis, since the COPD group, when compared with the nonCOPD group, has a lower glutathione level (Fig. 1B). In addition, some significant correlations were found between oxidative stress biomarkers (eg, glutathione) and 6MWD in the non-COPD group and between antioxidant biomarkers (eg, malondialdehyde) in the COPD group (see Table 4). Moreover, a significant correlation was found between leisure score and $\mathrm{F}_{\mathrm{ENO}}$, recognized as an oxidative biomarker that integrates both airway inflammation and lung function changes ${ }^{24,25}$ (see Table 4). Inflammation and apoptosis are also known as major causes of myopathy in subjects with COPD. ${ }^{68}$ These 2 hypotheses were not evaluated in the present paper.

No significant correlation was found between the BODE index and the measured oxidative stress biomarker data in both groups (see Table 4). These results were partially consistent with those of Folchini et al, ${ }^{35}$ who correlated BODE index and some oxidative stress biomarkers (glutathione, thiobarbituric acid-reactive substances, homocysteine, superoxide dismutase and catalase), and the only significant correlation was found between thiobarbituric acid-reactive substances and BODE index $(r=0.51)$ of the COPD group. ${ }^{35}$

How Can We Explain the Impairment of the COPD Smokers' QOL? Oxidative stress can be advanced as a hypothesis. In the present study, positive and significant correlation was found between the malondialdehyde and QOL score of the COPD group (see Table 4). This association, although internationally accepted for a long period of time, is currently under extensive research, due to the increasing appreciation of the relevant oxidative stress negative role in the prognosis and HRQOL of subjects with COPD. 6,74

\section{Conclusions}

Compared with the non-COPD group of smokers, the COPD group had a marked decrease in 6MWD and in QOL score. Stress oxidative biomarkers were correlated with 6MWD (malondialdehyde for the COPD group and glutathione for the non-COPD group) and QOL scores (malondialdehyde for the COPD group and $\mathrm{F}_{\mathrm{ENO}}$ for the non-COPD group).

\section{ACKNOWLEDGMENTS}

We thank Roxann Ouerfelli (English language program manager) and Professor Dhouha Boukeri for invaluable contributions to improvement of the quality of the writing in the present work.

\section{REFERENCES}

1. Celli BR, MacNee W. Standards for the diagnosis and treatment of patients with COPD: a summary of the ATS/ERS position paper. Eur Respir J 2004;23(6):932-946. 
Incapacity, Handicap, and Oxidative Stress Markers in Male Smokers

2. Global Initiative for Chronic Obstructive Lung Disease. Global strategy for the diagnosis, management, and prevention of chronic obstructive pulmonary disease. Updated 2015. http://www.goldcopd.org/ uploads/users/files/GOLD_Report_2015_Apr2.pdf. Accessed October 9, 2015.

3. Ben Moussa S, Sfaxi I, Tabka Z, Ben Saad H, Rouatbi S. Oxidative stress and lung function profiles of male smokers free from COPD compared to those with COPD: a case-control study. Libyan J Med 2014;9:23873.

4. Ben Saad H, Ben Amor L, Ben Mdella S, Ghannouchi I, Ben Essghair M, Bougmiza I, et al. The diagnosis of COPD is recommendation dependent. Tunis Med 2014;92(7):474-481.

5. MacNee W. Pathogenesis of chronic obstructive pulmonary disease. Proc Am Thorac Soc 2005;2(4):258-266; discussion 290-251.

6. Celli BR, Decramer M, Wedzicha JA, Wilson KC, Agustí A, Criner GJ, et al. An official American Thoracic Society/European Respiratory Society statement: research questions in chronic obstructive pulmonary disease. Am J Respir Crit Care Med 2015;191(7):e4-e27.

7. Singh SJ, Puhan MA, Andrianopoulos V, Hernandes NA, Mitchell $\mathrm{KE}$, Hill CJ, et al. An official systematic review of the European Respiratory Society/American Thoracic Society: measurement properties of field walking tests in chronic respiratory disease. Eur Respir J 2014;44(6):1447-1478.

8. Holland AE, Spruit MA, Troosters T, Puhan MA, Pepin V, Saey D, et al. An official European Respiratory Society/American Thoracic Society technical standard: field walking tests in chronic respiratory disease. Eur Respir J 2014;44(6):1428-1446.

9. Jones PW, Quirk FH, Baveystock CM, Littlejohns P. A self-complete measure of health status for chronic airflow limitation: the St. George's Respiratory Questionnaire. Am Rev Respir Dis 1992;145(6): 1321-1327.

10. Voorrips LE, Ravelli AC, Dongelmans PC, Deurenberg P, Van Staveren WA. A physical activity questionnaire for the elderly. Med Sci Sports Exerc 1991;23(8):974-979.

11. Celli BR, Cote CG, Marin JM, Casanova C, Montes de Oca M, Mendez RA, et al. The body-mass index, airflow obstruction, dyspnea, and exercise capacity index in chronic obstructive pulmonary disease. N Engl J Med 2004;350(10):1005-1012.

12. Kang M, Ragan BG, Park JH. Issues in outcomes research: an overview of randomization techniques for clinical trials. J Athl Train 2008;43(2):215-221.

13. Ben Saad H. The narghile and its effects on health. Part I: the narghile, general description and properties. Rev Pneumol Clin 2009; 65(6):369-375.

14. Ben Saad H, Préfaut C, Tabka Z, Zbidi A, Hayot M. The forgotten message from gold: FVC is a primary clinical outcome measure of bronchodilator reversibility in COPD. Pulm Pharmacol Ther 2008; 21(5):767-773.

15. Miller MR, Hankinson J, Brusasco V, Burgos F, Casaburi R, Coates A, et al. Standardisation of spirometry. Eur Respir J 2005;26(2):319-338.

16. Inonu H, Doruk S, Sahin S, Erkorkmaz U, Celik D, Celikel S, Seyfikli Z. Oxidative stress levels in exhaled breath condensate associated with COPD and smoking. Respir Care 2012;57(3):413-419.

17. Ben Saad H, Babba M, Boukamcha R, Ghannouchi I, Latiri I, Mezghenni $\mathrm{S}$, et al. Investigation of exclusive narghile smokers: deficiency and incapacity measured by spirometry and 6-minute walk test. Respir Care 2014;59(11):1696-1709.

18. Ben Saad H, Ben Hassen I, Ghannouchi I, Latiri I, Rouatbi S, Escourrou P, et al. 6-Min walk-test data in severe obstructive-sleepapnea-hypopnea-syndrome (OSAHS) under continuous-positive-airway-pressure (CPAP) treatment. Respir Med 2015;109(5):642-655.

19. Rouatbi S, Chouchene MA, Sfaxi I, Ben Rejeb M, Tabka Z, Ben Saad H. Fraction of exhaled nitric oxide (FeNO) norms in healthy Tunisian adults. Biomed Res Int 2014;2014:269670.
20. Kharitonov SA, Yates DH, Barnes PJ. Inhaled glucocorticoids decrease nitric oxide in exhaled air of asthmatic patients. Am J Respir Crit Care Med 1996;153(1):454-457.

21. Rossman MJ, Groot HJ, Reese V, Zhao J, Amann M, Richardson RS. Oxidative stress and COPD: the effect of oral antioxidants on skeletal muscle fatigue. Med Sci Sports Exerc 2013;45(7):1235-1243.

22. Cazzola M, Biscione GL, Pasqua F, Crigna G, Appodia M, Cardaci V, Ferri L. Use of 6-min and 12-min walking test for assessing the efficacy of formoterol in COPD. Respir Med 2008;102(10):1425-1430.

23. Waggiallah $\mathrm{H}$, Alzohairy $\mathrm{M}$. The effect of oxidative stress on human red cells glutathione peroxidase, glutathione reductase level, and prevalence of anemia among diabetics. N Am J Med Sci 2011;3(7):344-347.

24. American Thoracic Society, European Respiratory Society. ATS/ERS recommendations for standardized procedures for the online and offline measurement of exhaled lower respiratory nitric oxide and nasal nitric oxide. Am J Respir Crit Care Med 2005;171(8):912-930.

25. Haccuria A, Michils A, Michiels S, Van Muylem A. Exhaled nitric oxide: a biomarker integrating both lung function and airway inflammation changes. J Allergy Clin Immunol 2014;134(3):554-559.

26. Wanger J, Clausen JL, Coates A, Pedersen OF, Brusasco V, Burgos F, et al. Standardisation of the measurement of lung volumes. Eur Respir J 2005;26(3):511-522.

27. Ben Saad H, Selmi H, Hadj Mabrouk K, Gargouri I, Nouira A, Said Latiri H, et al. Spirometric "Lung Age" estimation for North African population. Egypt J Chest Dis Tuberc 2014;63(2):491-503.

28. Ben Saad H, Prefaut C, Tabka Z, Mtir AH, Chemit M, Hassaoune R, et al. 6-Minute walk distance in healthy North Africans older than 40 years: influence of parity. Respir Med 2009;103(1):74-84.

29. Sergysels R, Hayot M. Evaluation of exercise-induced dyspnea. Rev Pneumol Clin 1997;53(5):278-282.

30. American Thoracic Society, American College of Chest Physicians. ATS/ACCP Statement on cardiopulmonary exercise testing. Am J Respir Crit Care Med 2003;167(2):211-277.

31. Chetta A, Zanini A, Pisi G, Aiello M, Tzani P, Neri M, Olivieri D. Reference values for the 6-min walk test in healthy subjects 20-50 years old. Respir Med 2006;100(9):1573-1578.

32. Hinkle DE, Wiersma W, Jurs SG. Applied statistics for the behavioral sciences. Boston: Houghton Mifflin; 2003:750-756.

33. Ben Saad H, El Attar MN, Hadj Mabrouk K, Ben Abdelaziz A, Abdelghani A, Bousarssar M, et al. The recent multi-ethnic global lung initiative 2012 (GLI2012) reference values don't reflect contemporary adult's North African spirometry. Respir Med 2013; 107(12):2000-2008.

34. Joseph S, Pascale S, Georges K, Mirna W. Cigarette and waterpipe smoking decrease respiratory quality of life in adults: results from a national cross-sectional study. Pulm Med 2012;2012:868294.

35. Folchini F, Nonato NL, Feofiloff E, D’Almeida V, Nascimento O, Jardim JR. Association of oxidative stress markers and C-reactive protein with multidimensional indexes in COPD. Chron Respir Dis 2011;8(2):101-108.

36. Liu SF, Chin $\mathrm{CH}$, Wang CC, Lin MC. Correlation between serum biomarkers and BODE index in patients with stable COPD. Respirology 2009;14(7):999-1004

37. Bouchet C, Guillemin F, Hoang Thi TH, Cornette A, Briançon S. Validation of the St George's questionnaire for measuring the quality of life in patients with chronic obstructive pulmonary disease. Rev Mal Respir 1996;13(1):43-46.

38. Doruk S, Ozyurt H, Inonu H, Erkorkmaz U, Saylan O, Seyfikli Z. Oxidative status in the lungs associated with tobacco smoke exposure. Clin Chem Lab Med 2011;49(12):2007-2012.

39. Sutherland TJ, Cowan JO, Young S, Goulding A, Grant AM, Williamson $\mathrm{A}$, et al. The association between obesity and asthma: interactions between systemic and airway inflammation. Am J Respir Crit Care Med 2008;178(5):469-475. 
40. Donini LM, Poggiogalle E, Mosca V, Pinto A, Brunani A, Capodaglio P. Disability affects the 6-minute walking distance in obese subjects (BMI $\left.>40 \mathrm{~kg} / \mathrm{m}^{2}\right)$. PLoS One 2013;8(10):e75491.

41. Warkentin LM, Das D, Majumdar SR, Johnson JA, Padwal RS. The effect of weight loss on health-related quality of life: systematic review and meta-analysis of randomized trials. Obes Rev 2014;15(3): 169-182.

42. Ghannem H, Hadj Fredj A. Eating habits and cardiovascular risk factors. Epidemiologic study of the Tunisian Sahel. Presse Med 1999; 28(19):1005-1008.

43. Franssen FM, O'Donnell DE, Goossens GH, Blaak EE, Schols AM. Obesity and the lung: 5. obesity and COPD. Thorax 2008;63(12): 1110-1117.

44. Wiegman CH, Michaeloudes C, Haji G, Narang P, Clarke CJ, Russell KE, et al. Oxidative stress-induced mitochondrial dysfunction drives inflammation and airway smooth muscle remodeling in patients with chronic obstructive pulmonary disease. J Allergy Clin Immunol 2015;136(3):769-780.

45. Ziora D, Dworniczak S, Kaczmarczyk G, Jastrzebski D, Krzywiecki A, Kozielski J. Correlation of exhaled nitric oxide with nitrogen oxides and selected cytokines in induced sputum of chronic obstructive pulmonary disease patients. J Physiol Pharmacol 2007;58(Pt 2):791-799.

46. Heijdra YF, Pinto-Plata VM, Kenney LA, Rassulo J, Celli BR. Cough and phlegm are important predictors of health status in smokers without COPD. Chest 2002;121(5):1427-1433.

47. Gaki E, Kontogianni K, Papaioannou AI, Bakakos P, Gourgoulianis KI, Kostikas K, et al. Associations between BODE index and systemic inflammatory biomarkers in COPD. COPD 2011;8(6):408-413.

48. Fujimoto H, Asai K, Watanabe T, Kanazawa H, Hirata K. Association of six-minute walk distance (6MWD) with resting pulmonary function in patients with chronic obstructive pulmonary disease (COPD). Osaka City Med J 2011;57(1):21-29.

49. Cote CG, Casanova C, Marín JM, Lopez MV, Pinto-Plata V, de Oca $\mathrm{MM}$, et al. Validation and comparison of reference equations for the 6-min walk distance test. Eur Respir J 2008;31(3):571-578.

50. van Gestel AJ, Clarenbach CF, Stöwhas AC, Teschler S, Russi EW, Teschler H, Kohler M. Prevalence and prediction of exercise-induced oxygen desaturation in patients with chronic obstructive pulmonary disease. Respiration 2012;84(5):353-359.

51. Spruit MA, Watkins ML, Edwards LD, Vestbo J, Calverley PM, Pinto-Plata V, et al. Determinants of poor 6-min walking distance in patients with COPD: the ECLIPSE cohort. Respir Med 2010;104(6): 849-857.

52. Callens E, Graba S, Gillet-Juvin K, Essalhi M, Bidaud-Chevalier B, Peiffer $\mathrm{C}$, et al. Measurement of dynamic hyperinflation after a 6-minute walk test in patients with COPD. Chest 2009;136(6):1466-1472.

53. Gallego MC, Samaniego J, Alonso J, Sánchez A, Carrizo S, Marín JM. Dyspnea in COPD: relation to the MRC scale with dyspnea induced by walking and cardiopulmonary stress testing. Arch Bronconeumol 2002;38(3):112-116.

54. Miravitlles M, Soriano JB, García-Río F, Muñoz L, Duran-Tauleria E, Sanchez G, et al. Prevalence of COPD in Spain: impact of undiagnosed COPD on quality of life and daily life activities. Thorax 2009;64(10):863-868.

55. Jung YM, Lee H. Chronic obstructive pulmonary disease in Korea: prevalence, risk factors, and quality of life. J Korean Acad Nurs 2011;41(2):149-156.

56. Agusti A, Calverley PM, Celli B, Coxson HO, Edwards LD, Lomas DA, et al. Characterisation of COPD heterogeneity in the ECLIPSE cohort. Respir Res 2010;11:122.
57. Amorim PB, Stelmach R, Carvalho CR, Fernandes FL, CarvalhoPinto RM, Cukier A. Barriers associated with reduced physical activity in COPD patients. J Bras Pneumol 2014;40(5):504-512.

58. Carpes MF, Mayer AF, Simon KM, Jardim JR, Garrod R. The Brazilian Portuguese version of the London Chest Activity of Daily Living scale for use in patients with chronic obstructive pulmonary disease. J Bras Pneumol 2008;34(3):143-151.

59. Bentsen SB, Rokne B, Wahl AK. Comparison of health-related quality of life between patients with chronic obstructive pulmonary disease and the general population. Scand J Caring Sci 2013;27(4):905-912.

60. Ståhl E, Lindberg A, Jansson SA, Rönmark E, Svensson K, Andersson F, et al. Health-related quality of life is related to COPD disease severity. Health Qual Life Outcomes 2005;3:56.

61. Nitzan Kaluski D, Demem Mazengia G, Shimony T, Goldsmith R, Berry EM. Prevalence and determinants of physical activity and lifestyle in relation to obesity among schoolchildren in Israel. Public Health Nutr 2009;12(6):774-782.

62. Gomez-Pinilla F. The combined effects of exercise and foods in preventing neurological and cognitive disorders. Prev Med 2011; 52(Suppl 1):S75-S80.

63. Cote CG, Celli BR. BODE index: a new tool to stage and monitor progression of chronic obstructive pulmonary disease. Pneumonol Alergol Pol 2009;77(3):305-313.

64. Koechlin C, Maltais F, Saey D, Michaud A, LeBlanc P, Hayot M, Préfaut C. Hypoxaemia enhances peripheral muscle oxidative stress in chronic obstructive pulmonary disease. Thorax 2005;60(10): 834-841.

65. Enright PL, McBurnie MA, Bittner V, Tracy RP, McNamara R, Arnold A, et al. The 6-min walk test: a quick measure of functional status in elderly adults. Chest 2003;123(2):387-398.

66. Jenkins S, Cecins N, Camarri B, Williams C, Thompson P, Eastwood P. Regression equations to predict 6-minute walk distance in middle-aged and elderly adults. Physiother Theory Pract 2009;25(7):516-522.

67. Couillard A, Prefaut C. From muscle disuse to myopathy in COPD: potential contribution of oxidative stress. Eur Respir J 2005;26(4): 703-719.

68. Cielen N, Maes K, Gayan-Ramirez G. Musculoskeletal disorders in chronic obstructive pulmonary disease. Biomed Res Int 2014;2014: 965764.

69. Decramer M, Lacquet LM, Fagard R, Rogiers P. Corticosteroids contribute to muscle weakness in chronic airflow obstruction. Am J Respir Crit Care Med 1994;150(1):11-16.

70. Pitta F, Troosters T, Spruit MA, Probst VS, Decramer M, Gosselink R. Characteristics of physical activities in daily life in chronic obstructive pulmonary disease. Am J Respir Crit Care Med 2005;171(9): 972-977.

71. Roca M, Mihăescu T. Peripheral muscle dysfunction in chronic obstructive pulmonary disease. Pneumologia 2012;61(3):178-182.

72. Doucet M, Russell AP, Léger B, Debigaré R, Joanisse DR, Caron MA, et al. Muscle atrophy and hypertrophy signaling in patients with chronic obstructive pulmonary disease. Am J Respir Crit Care Med 2007;176(3):261-269.

73. Rabinovich RA, Ardite E, Troosters T, Carbó N, Alonso J, Gonzalez de Suso JM, et al. Reduced muscle redox capacity after endurance training in patients with chronic obstructive pulmonary disease. Am J Respir Crit Care Med 2001;164(7):1114-1118.

74. Grassi V, Carminati L, Cossi S, Marengoni A, Tantucci C. Chronic obstructive lung disease. Systemic manifestations. Recenti Prog Med 2003;94(5):217-226. 